\title{
ECOG is as independent predictor of the response to chemotherapy, overall survival and progression-free survival in carcinoma of unknown primary site
}

\author{
ROCÍO GRAJALES-ÁLVAREZ ${ }^{1}$, ANA MARTIN-AGUILAR ${ }^{1}$, JUAN A. SILVA ${ }^{1}$, \\ JAIME G. DE LA GARZA-SALAZAR ${ }^{2}$, ERIKA RUIZ-GARCÍA ${ }^{3}$, CÉSAR LÓPEZ-CAMARILLO ${ }^{4}$, \\ LAURENCE A. MARCHAT ${ }^{5}$ and HORACIO ASTUDILLO-DE LA VEGA ${ }^{6}$
}

\begin{abstract}
${ }^{1}$ Oncology Hospital, National Medical Center, ‘Century XXI’, IMSS, México City 06720; ${ }^{2}$ Clinic of Thoracic Oncology;
${ }^{3}$ Translational Medicine Laboratory, National Institute of Cancerology, México City 14080; ${ }^{4}$ Oncogenomics Laboratory, Autonomous University of México City, México City 03100; ${ }^{5}$ Molecular Biomedicine Program and Biotechnology Program, National School of Medicine and Homeopathy, Instituto Politecnico Nacional, México City 07320;

${ }^{6}$ Translational Research Laboratory, Oncology Hospital, National Medical Center, 'Century XXI', IMSS, México City 06720, México
\end{abstract}

Received September 28, 2016; Accepted December 20, 2016

DOI: $10.3892 /$ mco.2017.1209

\begin{abstract}
The aim of the present study was to determine whether age, gender, functional status, histology, tumor location, number of metastases, and levels of the tumor markers, lactate dehydrogenase (LDH) and albumin, are poor prognostic factors for the response to chemotherapy in patients with carcinoma of unknown primary site. A total of 149 patients diagnosed with carcinoma of unknown primary site that was histologically confirmed, and treated with chemotherapy in the Oncology Hospital, National Medical Center, 'Century XXI' IMSS, Mexico City, Mexico during the period between January 2002 to December 2009, were carefully selected for the present study. The analysis of 149 patients diagnosed with carcinoma of unknown primary site revealed that the liver was the organ with the highest frequency of metastases (33.5\%). The objective response rates to chemotherapy were $\sim 30.2 \%$. Notably, ECOG was an important predictor of response to chemotherapy $(\mathrm{P}=0.008)$. The median progression-free survival was 7.1 months. Upon multivariate analysis, the Eastern Cooperative Oncology Group (ECOG) Scale of Performance Status was observed as an independent predictor of progression $(\mathrm{P}<0.0001)$. The median overall
\end{abstract}

Correspondence to: Dr Horacio Astudillo-de la Vega, Translational Research Laboratory, Oncology Hospital, National Medical Center, 'Century XXI', Av. Cuauhtémoc 330, IMSS, México City 06720, México

E-mail: hastud2@aol.com

Key words: Eastern Cooperative Oncology Group, chemotherapy, overall survival, progression-free survival, carcinoma of unknown primary site survival was 14.2 months. The ECOG was also an independent predictor of mortality $(\mathrm{P}<0.0001)$. In conclusion, the data from the present study have demonstrated that ECOG is an independent predictor of a poor response to chemotherapy, lower overall survival and progression-free survival in carcinoma of unknown primary site.

\section{Introduction}

Cancer of unknown primary (CUP) is a heterogeneous group of malignancies that are defined as the presence of metastases, without identifying a primary tumor following an extensive evaluation of the patient (1). The identification of the primary tumor represents a diagnostic and therapeutic challenge: the antemortem frequency of detection of the primary site is $<20-30 \%$ (2), meanwhile CUP represents between 2.3 and $4.2 \%$ of adult cancers (3). In Mexico, 4,223 new cases of CUP were diagnosed in 2001, representing 4\% of cancer cases during that year (4). Unfortunately, the median survival rate, even in patients treated with cytotoxic agents, was $<1$ year (5). Chemotherapy has been the cornerstone in the treatment of CUP; however, establishment of the results has been difficult due to the heterogeneity of patients in the series. CUP treatment must be individualized according to the clinical setting, considering the favorable or unfavorable group that the patient belonged to prior to the therapeutic decision. However, the benefits of chemotherapy compared with best supportive care in the subgroups of poor prognosis have yet to be fully elucidated, and the optimal treatment regimen has not been determined (6). Several chemotherapy schemes have been successful in groups of patients with favorable clinical characteristics. However, most patients with CUP are in the unfavorable group, and this exhibits low rates of response to systemic treatment, which is decided empirically according to clinical and functional status. On the other hand, it has been 
proposed that clinicopathological features, including age, gender, functional status, weight loss, histology, tumor location, number of metastases and the levels of tumor markers, may represent relevant prognostic variables (7-14). These variables have not been obtained consistently, and so larger studies are required to validate specific clinical, pathological and molecular profiles in order to differentiate patients that are likely to benefit from treatment from those who would be likely to experience only deterioration in their quality of life. There are no well-established clinical and molecular markers for CUP, and therefore recognition of such markers is of vital importance in determining the best treatment option. The aim of the present study was to determine whether clinicopathological parameters were prognostic factors for the response to chemotherapy in patients with CUP. Overall survival, progression-free survival and response rates to chemotherapy were investigated in the present study.

\section{Patients and methods}

Patients. A total of 149 patients with CUP treated at the Oncology Hospital, National Medical Center 'Century XXI', IMSS, Mexico City, Mexico between January 2002 and December 2009 were retrospectively analyzed. Patients $>18$ years of age diagnosed with CUP, who were histologically confirmed and with any histological subtype, were carefully selected. Patients previously treated in other units, those with hematological, renal or liver failure at the time of inclusion, or those with the presence of a second neoplasm were excluded. The clinicopathological factors analyzed were: Age, gender, functional status, histology, tumor location, number of metastases, and the levels of the tumor markers, lactate dehydrogenase (LDH) and albumin.

Statistical analysis. Overall survival (OS) was defined as the lifetime in months from the start of treatment until the patient succumbed to mortality. Progression-free survival (PFS) was determined from the start of the treatment to the date on which the disease progressed, determined clinically or by imaging, either by increasing tumor volume or development of new lesions. Response criteria were as follows: Complete response (CR) indicated no measurable tumor by clinical analysis and/or by imaging; partial response (PR) referred to a reduction of $\geq 30 \%$ in the largest diameter of one of the target lesions compared with the baseline study; and stable disease (SD) referred to a measurable reduction in tumor volume of $<30 \%$ in maximum diameter, with no appearance of new lesions. Toxicity to treatment was determined according to the National Cancer Institute (NCI) Common Terminology Criteria for Adverse Events (CTCAE, https:// ctep.cancer.gov). For the statistical analysis, comparison between subgroups was performed using the Chi-square test for quantitative variables, and Fisher's exact test for qualitative variables. The analysis of OS and PFS was performed using the Kaplan-Meier method with confidence intervals (CIs) of $95 \%$. Statistical analysis was performed using SPSS software, version 17 (SPSS, Inc., Chicago, IL, USA). For univariate analysis, a statistical comparison of median survival with the $t$-test was used, and multivariate analysis was performed using the Cox model. Only the variables with
$\mathrm{P}<0.05$, on performing a univariate analysis, were included in the present study. Proportional hazards were analyzed using graphical and statistical methods. $\mathrm{P}<0.05$ was considered to indicate a statistically significant value.

\section{Results}

Patient characteristics. A cohort of 149 patients diagnosed with CUP treated between January 2002 and December 2009 were carefully selected for the present study. Table I shows the clinicopathological characteristics of the patients involved in this study. Of the patients, $60 \%$ received only one line of chemotherapy. The mean age was 56.9 years (range, 25-90) and the numbers of patients according to gender (51.67\% male, $48.32 \%$ female) were similar. A total of $65.7 \%$ of subjects had ECOG-1, whereas adenocarcinoma and squamous cell carcinoma accounted for $85.57 \%$ of the histologies. A total of $75 \%$ of the tumors had a poor degree of differentiation tumor activity, which was confirmed in 2-3 sites in $53.69 \%$ of the cases. Molecular analysis revealed that there was an elevation in the levels of the tumor marker, cancer antigen 125 (CA125), in $34.22 \%$ of cases, being the most frequent biomarker (16.77\%). A significant increase in the expression of lactate dehydrogenase ( $\mathrm{LDH}$ ) was identified in $41.6 \%$ of the patients, and the level of albumin decreased in $12.1 \%$ of the individuals.

Location of metastases. Table II describes the location of the various sites of metastases in patients. The most frequently observed locations were the liver (33.5\% of patients), neck (30.2\%), lung (24.8\%), supraclavicular (18.1\%), bone $(16.7 \%)$, axillar (15.4\%), peritoneum (14.0\%), mediastinum and retroperitoneum $(13.4 \%)$. Other less frequent locations $(<10 \%)$ were localized in the pleura, skin, groin, pelvis, central nervous system, small intestine, colon, pancreas, parotid, pericardium and adrenal. Tumor activity was reported in the spleen, stomach, breast and bone marrow in $1 \%$ of the patients.

Response rates. A total of 45 patients (30.2\%) demonstrated a response to chemotherapy, of whom 12 patients $(8.1 \%)$ presented with CR, and 33 patients (22.1\%) exhibited PR. SD was observed in 17 patients $(11.4 \%)$. Eighty-three patients $(55.7 \%)$ progressed during treatment, and 4 patients $(2.7 \%)$ did not exhibit any response. A total of 21 cases of mortality (14.1\%) were associated with a diagnostic confirmatory note in the record (Table III). Notably, univariate analysis showed that ECOG $(\mathrm{P}=0.004)$, elevated levels of LDH $(\mathrm{P}=0.03)$ and histology $(\mathrm{P}=0.031)$ were prognostic factors for the response to chemotherapy (Table IV). Subsequently, a multivariate analysis of prognostic factors of the response to chemotherapy was performed using a logistic regression model. Notably, the results demonstrated that the ECOG was significantly associated $(\mathrm{P}=0.008)$ with the chemotherapy response (Table V).

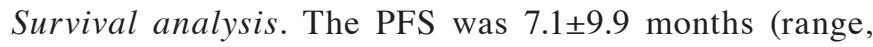
1-57 months) (Table VI). Survival curves for PFS derived using the Kaplan-Meier method are shown in Fig. 1. Notably, in the univariate analysis, the ECOG and LDH had high statistical significance, as predictive of PFS (Table VII). On performing a multivariate logistic regression, only ECOG was observed as 
Table I. Characteristics of patients with CUP from January 2002 to December 2009.

\begin{tabular}{|c|c|c|}
\hline Characteristic & Number of patients & $(\%)$ \\
\hline \multicolumn{3}{|l|}{ Gender } \\
\hline Male & 77 & 51.67 \\
\hline Female & 72 & 48.32 \\
\hline \multicolumn{3}{|l|}{ Age (years) } \\
\hline Median \pm SD & $56.94 \pm 12.69$ & - \\
\hline Range & $(25-90)$ & \\
\hline \multicolumn{3}{|l|}{ ECOG performance status } \\
\hline 0 & 0 & 0 \\
\hline 1 & 98 & 65.77 \\
\hline 2 & 49 & 32.88 \\
\hline 3 & 2 & 1.34 \\
\hline \multicolumn{3}{|l|}{ Histology } \\
\hline Squamous cell carcinoma & 18 & 12.08 \\
\hline Adenocarcinoma & 72 & 48.32 \\
\hline Neuroendocrine tumor & 2 & 1.34 \\
\hline Carcinoma & 57 & 38.25 \\
\hline \multicolumn{3}{|l|}{ Differentiation grade } \\
\hline Well differentiated & 4 & 2.68 \\
\hline Moderately differentiated & 34 & 22.81 \\
\hline Poorly differentiated & 111 & 74.49 \\
\hline \multicolumn{3}{|l|}{ Number sites of disease } \\
\hline 1 & 49 & 0.67 \\
\hline $2-3$ & 80 & 53.69 \\
\hline$>3$ & 20 & 13.42 \\
\hline Elevated tumor marker & 51 & 34.22 \\
\hline CEA & 23 & 15.43 \\
\hline AFP & 4 & 2.68 \\
\hline bHGC & 0 & 0 \\
\hline PSA & 2 & 1.34 \\
\hline CA125 & 25 & 16.77 \\
\hline CA19-9 & 6 & 4.02 \\
\hline LDH (>340 IU/l) & 62 & 41.60 \\
\hline Albumin $<3.4 \mathrm{~g} / \mathrm{dl}$ & 18 & 12.10 \\
\hline \multicolumn{3}{|l|}{$\begin{array}{l}\text { Number of chemotherapy } \\
\text { schemes }\end{array}$} \\
\hline 1 & 90 & 60.40 \\
\hline 2 & 42 & 28.18 \\
\hline 3 & 13 & 8.72 \\
\hline$>3$ & 4 & 2.68 \\
\hline
\end{tabular}

CUP, cancer of unknown primary; SD, standard deviation; LDH, lactate dehydrogenase; ECOG, Eastern Cooperative Oncology Group; AFP, $\alpha$-fetoprotein; CEA, carcinoembryonic antigen; BHGC, $\beta$-subunit of human chorionic gonadotropin; SA, prostate-specific antigen; CA125, cancer antigen 125; CA19-9, cancer antigen 19-9.

an independent factor of progression ( $\mathrm{P}<0.0001$; Table VIII). In addition, OS was 14.2 \pm 14.1 months (range, 1-84 months) as shown in Table IV. Survival curves derived using the
Table II. Location of tumor activity in patients with CUP $(n=149)$.

\begin{tabular}{|c|c|c|}
\hline Site of location & Number of cases & $(\%)$ \\
\hline Liver & 50 & 33.5 \\
\hline Cervical & 45 & 30.2 \\
\hline Lung & 37 & 24.8 \\
\hline Supraclavicular & 27 & 18.1 \\
\hline Bone & 25 & 16.7 \\
\hline Axilla & 23 & 15.4 \\
\hline Peritoneum & 21 & 14.0 \\
\hline Mediastinum & 20 & 13.4 \\
\hline Retroperitoneum & 20 & 13.4 \\
\hline Pleura & 11 & 7.3 \\
\hline Skin & 9 & 6.0 \\
\hline Groin & 8 & 5.3 \\
\hline Pelvis & 6 & 4.0 \\
\hline Central nervous system & 5 & 3.3 \\
\hline Small intestine & 3 & 2.0 \\
\hline Colon & 2 & 1.3 \\
\hline Pancreas & 2 & 1.3 \\
\hline Parotid & 2 & 1.3 \\
\hline Pericardium & 2 & 1.3 \\
\hline Adrenal & 2 & 1.3 \\
\hline Spleen & 1 & 0.67 \\
\hline Gastric & 1 & 0.67 \\
\hline Breast & 1 & 0.67 \\
\hline Bone marrow & 1 & 0.67 \\
\hline
\end{tabular}

Table III. Response rates to chemotherapy of patients with CUP (n=149).

Type of response Number

\begin{tabular}{lrr}
\hline Response & & \\
Complete & 12 & 8.1 \\
Parcial & 33 & 22.1 \\
Global & 45 & 30.2 \\
Progression & 83 & 55.7 \\
No response & 4 & 2.7 \\
Stable disease & 17 & 11.4 \\
Mortalities & 21 & 14.1
\end{tabular}

CUP, cancer of unknown primary.

Kaplan-Meier method for OS are shown in Fig. 2. The only independent predictor of mortality was the ECOG $(\mathrm{P}<0.0001)$; additional analysis revealed that there were no other clinical and pathological factors predictive of mortality.

Toxicity evaluation. Hematological toxicity, including anemia, thrombocytopenia, leukopenia and neutropenia of any grade, 
Table IV. Univariate analysis of prognostic factors of response to chemotherapy.

\begin{tabular}{|c|c|c|c|}
\hline Variable & $\mathrm{CR}(\%) \mathrm{n}=12$ & $\mathrm{PR}(\%) \mathrm{n}=33$ & P-value \\
\hline Gender & & & 0.75 \\
\hline Male & $5(41.7)$ & $18(54.5)$ & \\
\hline Female & $7(58.3)$ & $15(45.5)$ & \\
\hline ECOG & & & 0.004 \\
\hline 1 & $11(91.7)$ & $26(78.8)$ & \\
\hline 2 & $1(8.3)$ & $7(21.2)$ & \\
\hline 3 & $0(0)$ & $0(0)$ & \\
\hline Histology & & & 0.031 \\
\hline NET & $0(0)$ & $0(0)$ & \\
\hline Squamous cell carcinoma & $3(25.0)$ & $7(21.2)$ & \\
\hline Carcinoma & $4(33.3)$ & $10(30.3)$ & \\
\hline Adenocarcinoma & $5(41.7)$ & $16(48.5)$ & \\
\hline Differentiation grade & & & 0.46 \\
\hline Well differentiated & $0(0)$ & $1(3.0)$ & \\
\hline Moderately differentiated & $4(33.3)$ & $11(33.3)$ & \\
\hline Poorly differentiated & $8(66.7)$ & $21(63.7)$ & \\
\hline Tumor marker & & & 0.33 \\
\hline Normal & $10(83.3)$ & $23(69.7)$ & \\
\hline Elevated & $2(16.7)$ & $10(30.3)$ & \\
\hline LDH & & & 0.03 \\
\hline Normal & $11(91.7)$ & $18(54.5)$ & \\
\hline Elevated >340 IU/1 & $1(8.3)$ & $15(45.5)$ & \\
\hline Albumin & & & 0.43 \\
\hline Normal & $12(100)$ & $29(87.8)$ & \\
\hline Decreased $(<3.4 \mathrm{~g} / \mathrm{dl})$ & $0(0)$ & $4(12.2)$ & \\
\hline
\end{tabular}

CR, complete response; PR, partial response; ECOG, Eastern Cooperative Oncology Group; NET, neuroendocrine tumor; LDH, lactate dehydrogenase.

Table V. Multivariate logistic regression analysis of prognostic factors of response to chemotherapy.

\begin{tabular}{lcccc}
\hline Variable & $\beta$-value & OR & CI (95\%) & P-value \\
\hline ECOG & -1.13 & 0.42 & $0.13-0.74$ & 0.008
\end{tabular}

OR, odds ratio; CI, confidence interval; ECOG, Eastern Cooperative Oncology Group.

occurred in $43.6 \%$ of patients; grade 3 to 4 was observed in $21.5 \%$ of the patients. Gastrointestinal toxicity (nausea, vomiting, mucositis, diarrhea, constipation, anorexia) in any degree was observed in $67.8 \%$ of the patients, documented at grades 3 to 4 in $20.2 \%$ of cases. Dermatological toxicity was reported in $53.02 \%$ of the patients, with alopecia being the most common cause $(48.32 \%)$, and one case $(0.7 \%)$ documented severe dermatological toxicity secondary to hand-foot syndrome. In addition, $16.8 \%$ of the patients reported neurological toxicity (sensory neuropathy and/or motor), and 5 cases
(3.4\%) reached grade 3 to 4 . Almost two-thirds of the patients $(64.4 \%)$ expressed a specific degree of constitutional symptoms, and $12.7 \%$ of the cases exhibited severely limiting or incapacitating conditions.

\section{Discussion}

The present study is a retrospective analysis of 7 years' experience in the treatment of patients with CUP in our institution. The primary endpoint was to determine clinicopathological factors that may confer lower response rates and decreased survival rates in patients with CUP, in order to establish subgroups of high and low risk, and identify those in whom chemotherapy did not yield any clinical benefits, but only toxic effects. In the present analysis, objective response rates to treatment were $30.2 \%$, which was similar to those observed in the literature with platinum schemes (15-22). In schemes based on platinum and taxane, the response rates were 30-50\% (23-34), and reported response rates were $>50 \%$ (up to $79 \%$ ) in Phase II trials, which included a considerable number of patients at low risk (35-40), who were present in the minority in the present study. Of the study subjects, $>85 \%$ received treatment 
Table VI. Global survival and progression-free survival in patients with no known primary tumor $(n=149)$.

\begin{tabular}{lcc}
\hline Survival & Months & \pm SD \\
\hline $\begin{array}{l}\text { Overall survival } \\
\text { Median }\end{array}$ & 14.1 \\
Range & 14.2 & \\
Progression free survival & $1-84$ & 9.09 \\
Median & & \\
Range & 7.1 & \\
ECOG & $1-57$ & \\
1 & & \\
2 & $25.9(\mathrm{CI} 95 \%, 19.5-32.4)$ & \\
3 & $7.4(\mathrm{CI} 95 \%, 4.1-10.7)$ & \\
\hline
\end{tabular}

SD, standard deviation; CI, confidence Interval; ECOG, Eastern Cooperative Oncology Group.

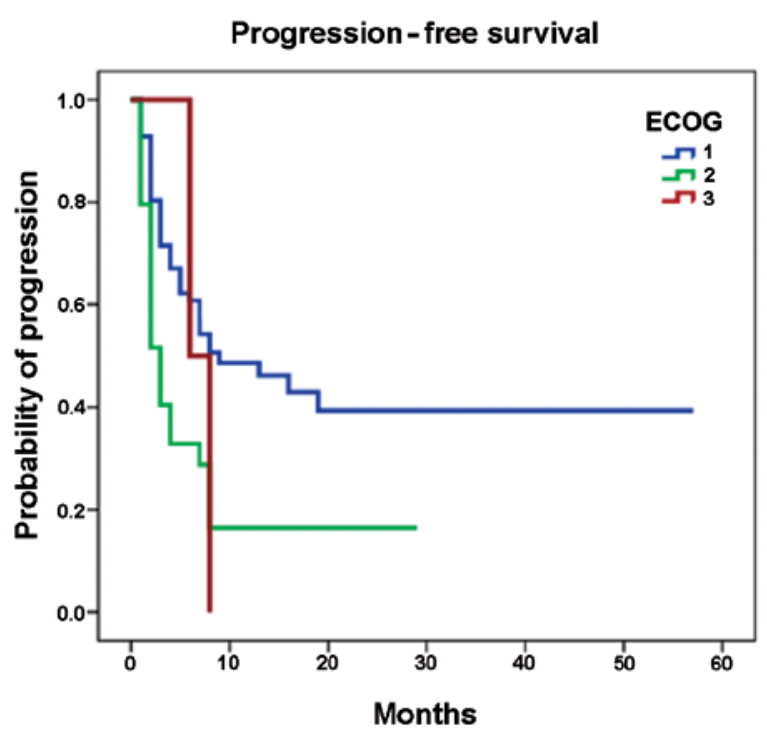

Figure 1. Kaplan-Meier curves for progression-free survival in 149 patients with CUP, according to ECOG. CUP, cancer of unknown primary; ECOG, Eastern Cooperative Oncology Group.

regimens based on platinum. It is important to note that, prior to 2004 , the use of taxanes was not common, and several of the schemes that were in use prior to this date are now useless. The median OS was 14.2 months, whereas the PFS was 7.1 months, also consistent with the trials. Approximately $40 \%$ of the patients received more than one line of treatment. At present, there is no set pattern of second-line chemotherapy in CUP. The use of multiple lines of treatment is subject to an appropriate assessment being made of the patient, and its recommendation is questionable; therefore, it was reserved for patients who had a good response rate with a previous scheme, and who were of excellent functional status. The weighting of risk-benefit and economic impact were not objectives of the present study. Regarding the clinicopathological factors of poor response to treatment, age, gender, ECOG, histology, grade of

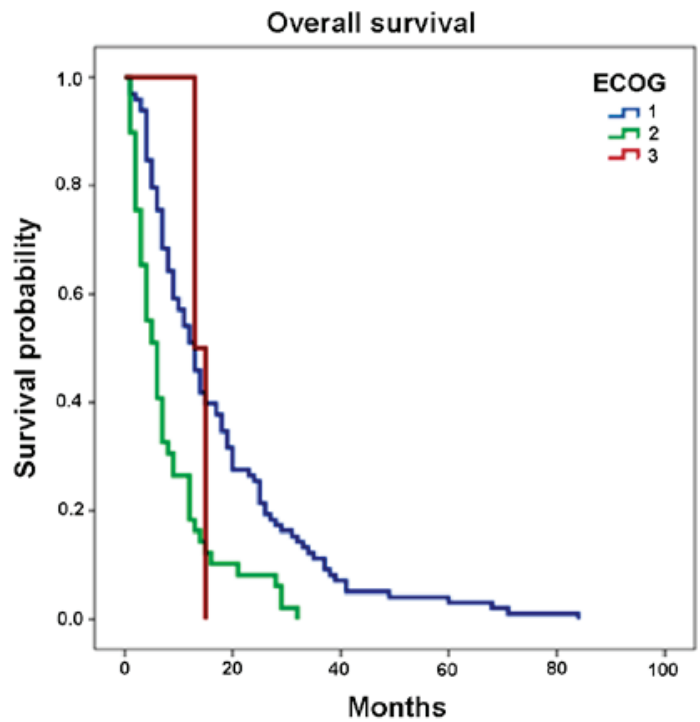

Figure 2. Kaplan-Meier curves for overall survival in 149 patients with CUP, according to ECOG. CUP, cancer of unknown primary; ECOG, Eastern Cooperative Oncology Group.

differentiation, number and location of metastases, elevation of tumor markers, elevated LDH and decreased albumin were analyzed. The results demonstrated that, in univariate analysis of response to treatment, the significant factors were ECOG-1, normal LDH and adenocarcinoma histology for a greater response to treatment; however, when performing multivariate logistic regression analysis, only ECOG proved to be an independent predictor of the response to treatment. Similarly, when analyzing the prognostic factors for OS and PFS, the ECOG was the only independent factor for these two characteristics. The other variables analyzed did not reach a statistically significant P-value. It should be noted that, according to the multivariate logistic regression analysis, the level of LDH was identified at the limit of statistical significance $(\mathrm{P}=0.054)$, and this may be due to the fact that patients were not stratified according to elevated levels of this protein. The ECOG as a predictor of a poor response to cytotoxic therapy in patients with CUP has been referred to in numerous studies that had similar aims $(8,10,12,22,41-44)$.

Several studies have identified prognostic factors associated with survival in patients with unknown primary cancer. However, there is, thus far, a solid classification system in place that enables the stratification of patients according to these characteristics in risk groups, since the groups of patients studied tend to be heterogeneous, and therefore the factors mentioned are inconsistent. The present study has revealed specific aspects of heterogeneity of the patients, including multiple histologies, and the grade of differentiation and application of various treatments. Adenocarcinoma and squamous cell histologies yielded higher rates of CR and PR for adenocarcinoma (41.7 and 48.5\%, respectively) compared with a CR of $33.3 \%$ and a PR of $30.3 \%$ for squamous cell carcinoma. Similarly, a poor differentiation grade represented $>60 \%$ of cases of objective responses to treatment. However, on performing the univariate analysis, none of these variables were revealed to be statistically significant. The data collection in retrospective studies, such as the present example, has a number of disadvantages: Usually, there is bias 
Table VII. Univariate analysis of prognostic factors of progression to chemotherapy.

\begin{tabular}{|c|c|c|c|c|}
\hline Variable & Progression $(\%) \mathrm{n}=83$ & $\mathrm{RR}$ & CI, $95 \%$ & P-value \\
\hline Gender & & & & 0.44 \\
\hline Male & $41(49.4)$ & & & \\
\hline Female & $42(50.6)$ & 0.95 & $0.71-1.27$ & \\
\hline \multicolumn{5}{|l|}{ ECOG } \\
\hline 1 & $46(55.4)$ & & & \\
\hline 2 & $35(42.2)$ & 0.65 & $0.49-0.86$ & 0.004 \\
\hline 3 & $2(2.4)$ & 0.71 & $0.59-0.85$ & 0.002 \\
\hline Histology & & & & 0.61 \\
\hline NET & $0(0)$ & & & \\
\hline Squamous cell carcinoma & $8(9.7)$ & & & \\
\hline Carcinoma & $33(39.7)$ & & & \\
\hline Adenocarcinoma & $42(50.6)$ & & & \\
\hline Differentiation grade & & & & 0.15 \\
\hline Well differentiated & $2(2.5)$ & & & \\
\hline Moderately differentiated & $15(18.0)$ & & & \\
\hline Poorly differentiated & $66(79.5)$ & & & \\
\hline Number of sites of disease & & & & 0.29 \\
\hline 1 & $24(28.9)$ & & & \\
\hline $2-3$ & $47(56.7)$ & & & \\
\hline$>3$ & $12(14.4)$ & & & \\
\hline Location of disease & & & & 0.122 \\
\hline Peritoneum & $8(9.6)$ & 0.67 & $0.47-0.95$ & 0.1 \\
\hline Lung, pleura & $14(16.9)$ & 0.80 & $0.57-1.13$ & 0.27 \\
\hline Cervical & $19(22.9)$ & 0.88 & $0.63-1.22$ & 0.48 \\
\hline Axilla, SCV & $8(9.6)$ & 0.97 & $0.60-1.56$ & 0.90 \\
\hline Liver & $21(25.3)$ & 1.13 & $0.81-1.56$ & 0.43 \\
\hline Bone & $5(5.8)$ & 1.42 & $0.84-2.40$ & 0.13 \\
\hline Mediastinum & $4(4.8)$ & 2.26 & $0.41-12.4$ & 0.21 \\
\hline Retroperitoneum & $4(5.1)$ & 2.31 & $0.52-12.7$ & 0.23 \\
\hline Tumor marker & & & & 0.52 \\
\hline Normal & $49(59.0)$ & & & \\
\hline Elevated & $34(41.0)$ & 0.75 & $0.56-0.99$ & \\
\hline LDH & & & & 0.031 \\
\hline Normal & $42(50.6)$ & & & \\
\hline Elevated (>340 IU/1) & $41(49.4)$ & 0.73 & $0.55-0.96$ & \\
\hline Albumin & & & & 0.13 \\
\hline Normal & $70(84.3)$ & & & \\
\hline Decreased $(<3.4 \mathrm{~g} / \mathrm{dl})$ & $13(15.7)$ & 0.74 & $0.53-1.02$ & \\
\hline
\end{tabular}

RR, relative risk; CI, confidence interval; ECOG, Eastern Cooperative Oncology Group; NET, neuroendocrine tumor; SCV, supraclavicular; CNS, central nervous system; LDH, lactate dehydrogenase.

Table VIII. Multivariate logistic regression analysis of prognostic factors of progression.

\begin{tabular}{lcccc}
\hline Variable & $\beta$-value & OR & CI, 95\% & P-value \\
\hline ECOG & -1.226 & 0.37 & $1.4-6.08$ & $<0.0001$ \\
\hline
\end{tabular}

OR, odds ratio; CI, confidence interval; ECOG, Eastern Cooperative Oncology Group. in the catch; there are not properly specified degrees of toxicity in all cases; and there is the possibility of errors emerging as a consequence of subjective assessment.

It would be imperative in subsequent prospective analyses to reduce the heterogeneity of the study population, excluding patients from well-defined subgroups with good prognosis with specific treatment indications, and yet without losing sight of those patients from established groups of potentially curable disease or under good control, as lymphomas, germ cell tumors, 
breast cancer or neuroendocrine tumors (45). At present, there are no Phase III studies comparing systemic treatment with best supportive care in patients with unfavorable risk factors. Prospective clinical trials are required to establish the optimal treatment for each patient, and to clearly define the group of patients who will benefit from cytotoxic treatment.

Treatment of patients with CUP remains a challenge for oncology, and requires a multidisciplinary approach. The objective should be focused on preventing the requirement for empirical management, in this context, with the advent of molecular and genetic profiles that are currently under study for this complex neoplasm (46-51) and the development of therapeutics based on a combination of molecular biology, microarray and immunohistochemistry approaches, and therefore clinical and pathological factors will have an essential role in the management of these patients.

Taken together, the ECOG performance status is an independent predictor of poor response to chemotherapy, and lower OS and PFS in patients with CUP.

\section{Acknowledgements}

The authors acknowledge the National Medical Center 'Century XXI', IMSS, México for their support.

\section{References}

1. Pavlidis $\mathrm{N}$ and Fizazi K: Carcinoma of unknown primary (CUP). Crit Rev Oncol Hematol 69: 271-278, 2009.

2. Pavlidis N, Briasoulis E, Hainsworth $\mathrm{J}$ and Greco F: Diagnostic and therapeutic management of cancer of an unknown primary. Eur J Cancer 39: 1990-2005, 2003.

3. Krementz ET, Cerise EJ, Foster DS and Morgan L Jr: Metastases of undetermined source. Curr Pobl Cancer 4: 4-37, 1979.

4. Bosetti C, Rodríguez T, Chatenoud L, Bertuccio P, Levi F, Negri E and La Vecchia C: Trends in cancer mortality in Mexico, 1981-2007. Eur J Cancer Prev 20: 355-363, 2011.

5. Pentheroukadis G, Briasoulis E and Pavlidis N: Cancer of unknown primary site: Missing primary or missing biology? Oncologist 12: 418-425, 2007.

6. Sporn JR and Greenberg BR: Empirical chemotherapy for adenocarcinoma of unknown primary site. Semin Oncol 20: 261-267, 1993.

7. Culine S: Prognostic factors in unknown primary cancer. Semin Oncol 36: 60-64, 2009.

8. Abbruzzese JL, Abbruzzese MC, Hess KR, Raber MN, Lenzi R and Frost P: Unknown primary carcinoma: Natural history and prognostic factors in 657 consecutive patients. J Clin Oncol 12: 1272-1280, 1994.

9. Hess KR, Abbruzzese MC, Lenzi R, Raber MN and Abbruzzese JL: Classification and regression tree analysis of 1,000 consecutive patients with unknown primary carcinoma. Clin Cancer Res 5: 3403-3410, 1999.

10. Lortholary A, Abadie-Lacourtoisie S, Guérin O, Mege M, Rauglaudre GD and Gamelin E: Cancers of unknown origin: 311 cases. Bull Cancer 88: 619-627, 2001 (In French).

11. Culine S, Kramar A, Saghatchian M, Bugat R, Lesimple T, Lortholary A, Merrouche Y, Laplanche A and Fizazi K; French Study Group on Carcinomas of Unknown Primary: Development and validation of a prognostic model to predict the length of survival in patients with carcinomas of an unknown primary site. J Clin Oncol 20: 4679-4683, 2002.

12. Seve P, Ray-Coquard I, Trillet-Lenoir V, Sawyer M, Hanson J, Broussolle C, Negrier S, Dumontet C and Mackey JR: Low serum albumin levels and liver metastases are powerful prognostic markers for survival in patients with carcinomas of unknown primary site. Cancer 107: 2698-2705, 2006.

13. Lenzi R, Abbruzzese J, Amato R, et al: Cisplatin, 5-fluorouracil and follinic acid for the treatment of carcinoma of unknown primary: A phase II study. Proc Am Soc Clin Oncol 10: 301, 1991.
14. Farrugia DC, Norman AR, Nicolson MC, Gore M, Bolodeoku ED, Webb A and Cunningham D: Unknown primary carcinoma: Randomized studies are needed to identify optimal treatments and their benefits. Eur J Cancer 32A: 2256-2261, 1996.

15. Rigg A, Cunningham D, Gore M, Hill M, O'Brien M, Nicolson M, Chang J, Watson M, Norman A, Hill A, Oates J, et al: A phase I/II study of leucovorin, carboplatin and 5-fluorouracil (LCF) in patients with carcinoma of unknown primary site or advanced oesophagogastric/pancreatic adenocarcinomas. Br J Cancer 75: 101-105, 1997.

16. Pavlidis N, Kosmidis P, Skarlos D, Brissoulis E, Beer M, Theoharis D, Bafaloukos D, Maraveyas A and Fountzilas G: Subsets of tumors responsive to cisplatin or carboplatin combinatios in patients with carcinoma of unknown primary site. A hellenic cooperative oncology group study. Ann Oncol 3: 631-634, 1992.

17. Briasoulis E, Tsavaris N, Fountzilas G, Athanasiadis A, Kosmidis P, Bafaloukos D, Skarlos D, Samantas E and Pavlidis N: Combination regimen with carboplatin, epirubicin and etoposide in metastatic carcinomas of unknown primary site: A Hellenic Co-oncology group phase II study. Oncology 55: 426-430, 1998.

18. Warner E, Goel R, Chang J, Chow W, Verma S, Dancey J, Franssen E, Dulude H, Girouard M, Correia J and Gallant G: A mulicenter phase II study of carboplatin and prolonged oral etoposide in the treatment of cancer of unknown primary site (CUPS). Br J Cancer 77: 2376-2380, 1998.

19. Voog E, Merrouche Y, Trillet-Lenoir V, Lasset C, Peaud PY, Rebattu P and Negrier S: Multicentric phase II study of cisplatin and etoposide in patients with metastatic carcinoma of unknown primary. Am J Clin Oncol 23: 614-616, 2000.

20. Macdonald AG, Nicolson MC, Samuel LM, Hutcheon AW and Ahmed FY: A phase II study of mitomycin C, cisplatin and continuous infusion 5-fluorouracil (MCF) in the treatment of patients with carcinoma of unknown primary site. Br J Cancer 86: 1238-1242, 2002.

21. Piga A, Gesuita R, Catalano V, Nortilli R, Getto G, Cardillo F, Giorgi F, Riva N, Porfiri E, Montironi R, et al: Identification of clinical prognostic factors in patients with unknown primary tumors treated with a platinum-based combination. Oncology 69: 135-144, 2005.

22. Pittman KB, Olver IN, Koczwara B, Kotasek D, Patterson WK, Keefe DM, Karapetis CS, Parnis FX, Moldovan S, Yeend SJ, et al: Gemcitabine and carboplatin in carcinoma of unknown primary site: A phase II Adelaide cancer trials and education collaborative study. Br J Cancer 95: 1309-1313, 2006.

23. Hainsworth JD, Erland JB, Kalman LA, Schreeder MT and Greco FA: Carcinoma of unknown primary site: Treatment with 1-h paclitaxel, carboplatin, and extended-schedule etoposide. J Clin Oncol 15: 2385-2393, 1997.

24. Briasoulis E, Kalofonos H, Bafaloukos D, Samantas E, Fountzilas G, Xiros N, Skarlos D, Christodoulou C, Kosmidis P and Pavlidis N: Carboplatin plus paclitaxel in unknown primary carcinoma: A phase II study. The Hellenic cooperative oncology group study. J Clin Oncol 18: 3101-3117, 2000.

25. Greco FA, Burris HA III, Erland JB, Gray JR, Kalman LA, Schreeder MT and Hainsworth JD: Carcinoma of unknown primary site. Cancer 89: 2655-2660, 2000.

26. Bouleuc C, Saghatchian M, Di Tullio L, Louvet CH, Levy E, Di Palma M, et al: A multicenter phase II study of docetaxel and cisplatin in the treatment of cancer of unknown primary site. Proc Am Soc Clin Oncol 137b: 2298, 2001.

27. Darby A, Richardson L, Nokes L, Harvey M, Hassan A and Iveson T: Phase II study of single agent docetaxel in carcinoma of unknown primary site. Proc Am Soc Clin Oncol 100b: 2151, 2001.

28. Gothelf A, Daugaard G and Nelausen K: Paclitaxel, cisplatin and gemcitabine in the treatment of unknown primary tumours, a phase II study. ESMO 25: 88, 2002.

29. Greco FA, Burris HA III, Litchy S, Barton JH, Bradof JE, Richards P, Scullin DC Jr, Erland JB, Morrissey LH and Hainsworth JD: Gemcitabine, carboplatin, and paclitaxel for patients with carcinoma of unknown primary site: A Minnie pearl cancer research network study. J Clin Oncol 20: 1651-1656, 2002.

30. Greco FA, Rodriguez GI, Shaffer DW, Hermann R, Litchy S, Yardley DA, Burris HA III, Morrissey LH, Erland JB and Hainsworth JD: Carcinoma of unknown primary site: Sequential treatment with paclitaxel/carboplatin/etoposide and gemcitabine/ irinotecan: A Minnie pearl cancer research network phase II trial. Oncologist 9: 644-652, 2004. 
31. Park YH, Ryoo BY, Choi SJ, Yang SH and Kim HT: A phase II study of paclitaxel plus cisplatin chemotherapy in an unfavourable group of patients with cancer of unknown primary site. Jpn J Clin Oncol 34: 681-685, 2004

32. Pouessel D, Culine S, Becht C, Ychou M, Romieu G, Fabbro M, Cupissol D and Pinguet F: Gemcitabine and docetaxel as front-line chemotherapy in patients with carcinoma of an unknown primary site. Cancer 100: 1257-1261, 2004.

33. El-Rayes BF, Shields AF, Zalupski M, Heilbrum LK, Jain V, Terry D, Ferris AM and Philip PA: A phase II study of carboplatin and paclitaxel in adenocarcinoma of unknown primary. Am J Clin Oncol 28: 152-156, 2005.

34. Hainsworth JD, Spigel DR, Litchy S and Greco FA: Phase II trial of paclitaxel, carboplatin, and etoposide in advanced poorly differentiated neuroendocrine carcinoma: A Minnie pearl cancer research network study. J Clin Oncol 24: 3548-3554, 2006.

35. van der Gaast A, Verweij J, Henzen-Logmans SC, Rodenburg CJ and Stoter G: Carcinoma of unknown primary: Identification of a treatable subset? Ann Oncol 1: 119-122, 1990.

36. Hainsworth JD, Johnson DH and Greco FA: The role of etoposide in the treatment of poorly differenciated carcinoma of unknown primary site. Cancer 67 (Suppl 1): S310-S314, 1991.

37. Khansur T, Allred C, Little D and Anand V: Cisplatin and 5-fluorouracil for metastatic squamous cell carcinoma from unknown primary. Cancer Invest 13: 263-266, 1995.

38. Greco FA, Vaughn WK and Hainsworth JD: Advanced poorly differenciated carcinoma of unknown primary site: Recognition of a treatable syndrome. Ann Intern Med 104: 547-553, 1986.

39. Falkson CI and Cohen GL: Mitomycin, epirubicin and cisplatin versus mitomycin-C alone as therapy for carcinoma ok unknown primary origin. Oncology 55: 116-121, 1998.

40. Guardiola E, Pivot X, Tchicknavorian X, Magne N, Otto J, Thyss A and Schneider M: Combination of cisplatin-doxorubicin-cyclophosphamide in adenocarcinoma of unknown primary site: A phase II trial. Am J Clin Oncol 24: 372-375, 2001

41. van der Gaast A, Verweij J, Planting AS, Hop WC and Stoter G: Simple prognostic model to predict survival in patients with undifferentiated carcinoma of unknown primary site. J Clin Oncol 13: 1720-1725, 1995.
42. Kambhu SA, Kelsen DP, Fiore J, Niedzwiecki D, Chapman D, Vinciguerra V and Rosenbluth R: Metastatic adenocarcinoma of unknown primary site. Prognostic variables and treatment results. Am J Clin Oncol 13: 55-60, 1990.

43. Seve P, Sawyer M, Hanson J, Broussolle C, Dumontet C and Mackey JR: The influence of comorbidities, age, and performance status on the prognosis and treatment of patients with metastatic carcinoma of unknown primary site: A population-based study. Cancer 106: 2058-2066, 2006.

44. Pasterz R, Savaraj N and Burgess M: Prognostic factors in metastatic carcinoma of unknown primary. J Clin Oncol 4: 1652-1657, 1986.

45. Lenzi R, Hess KR, Abbruzzese MC, Raber MN, Ordoñez NG and Abbruzzese JL: Poorly differenciated carcinoma and poorly differenciated adenocarcinoma of unknown origin: Favorable subsets of patients with unknown-primary carcinoma? J Clin Oncol 15: 2056-2066, 1997.

46. Varadhachary GR, Talantov D, Raber MN, Meng C, Hess KR, Jatkoe T, Lenzi R, Spigel DR, Wang Y, Greco FA, et al: Molecular profiling of carcinoma of unknown primary and correlation with clinical evaluation. J Clin Oncol 26: 4442-4448, 2008.

47. Pentheroukadis G, Golfinopoulos V and Pavlidis N: Swithing benchmarks in cancer of unknown primary: From autopsy to microarray. Eur J Cancer 43: 2026-2036, 2007.

48. Fizazi K: Treatment of patients with specific subsets of carcinoma of an unknown primary site. Ann Oncol 17 (Suppl 10): x177-x180, 2006

49. Varadhachary GR and Greco FA: Overview of patient management and future directions in unknown primary carcinoma. Semin Oncol 36: 75-80, 2009.

50. Viale $G$ and Mastropasqua MG: Diagnostic and therapeutic management of carcinoma of unknown primary: Histopathological and molecular diagnosis. Ann Oncol 17 (Suppl 10): x163-x167, 2006.

51. van de Wouw AJ, Jansen RL, Speel EJ and Hillen HF: The unknown biology of the unknown primary tumour: A literature review. Ann Oncol 14: 191-196, 2003. 